\title{
The importance of sports medicine for the Olympic Games and the value of ESSKA
}

\author{
Lars Engebretsen
}

Published online: 27 April 2010

(C) Springer-Verlag 2010

Injuries play major roles in the outcome of the Olympic Games, not only for national pride, but primarily for the individual athlete hit by a sudden catastrophe. As the IOC head of research during the Vancouver games, this became clear to me on the very first day of competition. Even though less than $10 \%$ of the 2,700 athletes suffered an injury, which needed to be seen by a sports medicine physician, as many as 30 athletes sustained major injuries leading to long-standing disability. Was this a surprise to me? Well, only a handful of the sports actually had injury incidence data from high level competitions. Almost none had data on risk factors for injury and had done studies to see the effectiveness of a reduction of the risk factors. The International Skiing Federation (FIS) has put many resources into evaluating the serious injury incidences and their risk factors [2, 3]. The study by Florenes et al. is the first large cohort study to examine the overall injury risk and detailed injury pattern among World Cup alpine skiers during the competitive season. The main findings were that the injury rate for elite alpine skiers was higher than previously reported, that the injury rate increased with increased skiing speed, and that the absolute and relative injury rate was higher among men compared with women. The knee was the most commonly injured body part, with a

L. Engebretsen $(\bowtie)$

Oslo Sports Trauma Research Center and Orthopedic Center,

Ullevaal University Hospital, Oslo, Norway

e-mail: lars.engebretsen@medisin.uio.no majority of severe injuries. Notably, among World Cup alpine skiers as many as $38 \%$ of all time-loss injuries caused an absence of more than 28 days. The entire project is funded by the International Skiing Federation (FIS), which is to be commended for their proactive work in injury prevention. They have compiled a comprehensive register of injuries in the World Cup, which will form the basis for their injury prevention work in the future. Based on the van Mechelen model [6], FIS has carried out the first step in the prevention hierarchy; the incidence rate is now known, research is now ongoing for studying risk factors, and soon they should be able to carry out controlled prevention studies.

There are other model international federations doing this work. The International Athletic Federation (IAAF), the International Swimming Federation (FINA), the International Ice hockey Federation (IHF), and FIFA, just to name a few $[1,4,5]$.

When the individual athlete suffered an injury in Vancouver, they were treated wonderfully well by the Canadian sports medicine crew, which included many orthopedic surgeons who volunteered their time to work for the Olympic Games. These orthopedic surgeons have benefited from a solid framework of Canadian education. However, even though their national educational system offers excellent basic training, the comprehensive knowledge necessary for dealing with injuries to the Olympic athlete and their likes must be supplemented by the educational tools offered by organizations such as ESSKA, and our worldwide sister organizations in ISAKOS, AOSSM, APOSSM, and SLARD. Such tools are for ESSKA members represented by our flagship KSSTA, our web-based teaching tools and not the least the literature offered by the ESSKA committees during the Oslo meeting: 


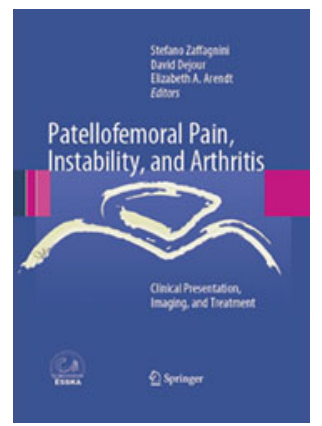

The brand-new book on Patello-femoral Pain, Instability and Arthritis by Stefano ZAFFAGNINI, David DEJOUR and Elizabeth ARENDT. This book reviews general features of clinical examination and global evaluation techniques. Various conservative and surgical treatment approaches for each of the three presentations-pain, instability, and arthritis-are then explained and assessed. It is hoped that this book will serve as an informative guide for the practitioner when confronted with disorders of the patello-femoral joint.

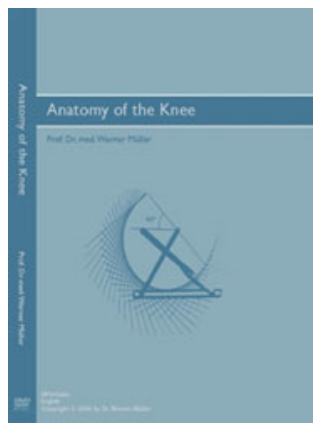

Werner MUELLER, internationally renowned and rewarded for his merits and significant contributions to the specialty of sports medicine has dedicated this state-of-the-art document on Anatomy of the Knee to all orthopedic surgeons. Chapters include kinematics, medial anatomy, Intra-articular patello-femoral anatomy, lateral anatomy, and posterior anatomy.

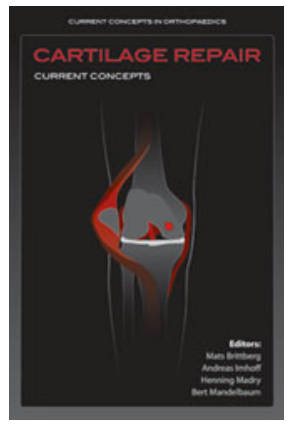

As a result of its 2-year activity for the period 2008-2010, the ESSKA Cartilage Committee, under the leadership of Henning MADRY and Mats BRITTBERG, is proud to offer this book on Cartilage Repair to all the Congress participants and later onto all ESSKA members.

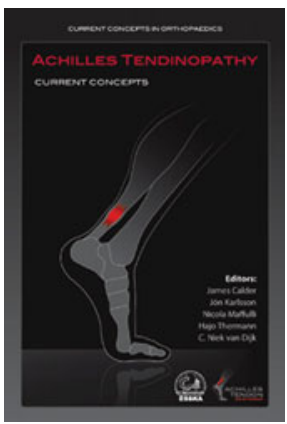

As a result of similar activity during 2008-2010, the Achilles Tendon Study Group (ATSG), under the leadership of Niek van DIJK, James CALDER, Hajo THERMAN, Nicola MAFFULLI, and Jon KARLSSON will present their second tendon rupture treatment is already a classic work. This book is concerned with the chronic Achilles tendon. Written by the best authorities in this field, the book will give you the latest in diagnosis and treatments.

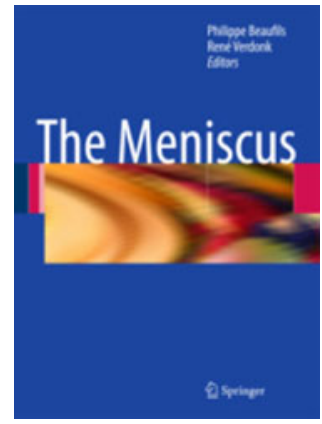

Finally, the brand new book The Meniscus, by Rene VERDONK and Philippe BEAUFILS will also be launched in Oslo. This clinical guide provides a special focus on the normal meniscal mechanism, body, and function. Meniscal pathology and therapy are depicted in detail, followed by the presentation of long-term experience of meniscal transplantation and a look into the future of meniscal surgery.

The leadership taken by ESSKA in these educational efforts is paramount to our existence as an international, educational organization. These tools will improve your knowledge and skills on how to diagnose and treat serious injuries similar to the injuries sustained by the Olympians in Whistler in February. However, you may not have sufficient knowledge on how to reduce these serious injuries. One of my tasks as the ESSKA President over the last 2 years has been to introduce and emphasize the current knowledge on injury prevention and health protection and suggest new areas of research. The leaders among you should put this task upon yourselves. AOSSM has launched "Stop Sports Injuries" website. Similar information is available on an European websites as well (http://www.ostrc.no).

It has been a wonderful experience to serve as your ESSKA President over these last 2 years. I have travelled Europe and met many of you and seen with my 
own eyes the tremendous efforts and progress made by you and your colleagues in education, research, and clinical work. The ESSKA committees have never been more active, and we have never before involved more individuals in our work. The ESSKA organization is much strengthened by our increasingly effective office in Luxembourg, and we have been able to join the ESSKA and KSSTA offices for the first time. We are now on firm ground, and Niek van Dijk as your new President can launch his new projects while making sure that ESSKA is consolidated as a leading sports medicine and trauma society in Europe.

\section{References}

1. Dvorak J, Junge A, Grimm K, Kirkendall D (2007) Medical report from the 2006 FIFA World Cup Germany. Br J Sports Med 41:578-581
2. Flørenes TW, Bere T, Nordsletten L, Heir S, Bahr R (2009) Injuries among male and female World Cup alpine skiers. Br J Sports Med 43:973-978

3. Flørenes TW, Nordsletten L, Heir S, Bahr R (2009) Recording injuries among elite skiers and snowboarders-a methodological study. Scand J Med Sci Sports. 18 Dec 2009 [Epub ahead of print]

4. Junge A, Engebretsen L, Mountjoy ML, Alonso JM, Renström PA, Aubry MJ, Dvorak J (2009) Sports injuries during the Summer Olympic Games 2008. Am J Sports Med 37:2165-2172

5. Mountjoy M, Gordon I, McKeown J, Constantini N (2009) Medical complications of an aquatic innovation. Br J Sports Med 43:979-980

6. van Mechelen W, Hlobil H, Kemper HC (1992) Incidence, severity, aetiology and prevention of sports injuries. A review of concepts. Sports Med 14:82-99 